University of Chicago Law School

Chicago Unbound

Public Law and Legal Theory Working Papers

Working Papers

2016

\title{
Acts that Legitimate: Widening the Array of Predicate Policing Practices
}

Aziz Huq

Jonathan Jackson

Rick Trinkner

Follow this and additional works at: https://chicagounbound.uchicago.edu/public_law_and_legal_theory

Part of the Law Commons

Chicago Unbound includes both works in progress and final versions of articles. Please be aware that a more recent version of this article may be available on Chicago Unbound, SSRN or elsewhere.

\section{Recommended Citation}

Aziz Huq, Jonathan Jackson \& Rick Trinkner, "Acts that Legitimate: Widening the Array of Predicate Policing Practices," University of Chicago Public Law \& Legal Theory Paper Series, No. 570 (2016).

This Working Paper is brought to you for free and open access by the Working Papers at Chicago Unbound. It has been accepted for inclusion in Public Law and Legal Theory Working Papers by an authorized administrator of Chicago Unbound. For more information, please contact unbound@law.uchicago.edu. 


\section{CHICAGO}

Public LAW AND Legal THEORY WORKING PAPER NO. 570

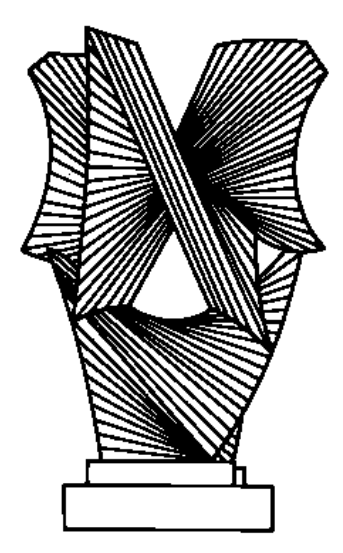

\section{ACTS THAT LEGITIMATE: WIDENING THE ARRAY OF PREDICATE POLICING PRACTICES}

Aziz Huq, Jonathan Jackson \& Rick Trickner

THE LAW SCHOOL

THE UNIVERSITY OF CHICAGO

March 2016 


\title{
Acts that Legitimate: Widening the Array of Predicate Policing Practices
}

\author{
Aziz Huq, Chicago Law School \\ Jonathan Jackson ${ }^{l}$, Department of Methodology, LSE \\ Rick Trickner, Yale Law School
}

\begin{abstract}
Procedural justice theory predicts a relationship between police behavior, individuals' normative evaluation of police, and decisions to comply with laws. Yet, prior studies of procedural justice have rather narrowly defined the potentially relevant predicates of police behavior. This study expands the scope of procedural justice theory by considering a broad array of policing components, including unobserved actions such as electronic surveillance, respecting the limits of one's legal authority, and the unequal or equal distribution of policing resources between different groups. Analyzing data from a national probability sample of adults in England and Wales, we (a) present a comprehensive investigation of the heterogeneous elements of policing related to legitimacy judgments and (b) contribute to debate about the nature of legitimacy.
\end{abstract}

Key words: Policing, Procedural Justice, Distributive Justice, Surveillance, Legitimacy, Police-citizen Encounters. 


\section{Introduction}

In the past twenty-five years, research into policing has grappled increasingly with the problem of legitimacy. Prompted by Tyler's (2006) groundbreaking work, criminologists have recognized that subjects of state-sponsored forces must see the police as right, proper and entitled to be obeyed (Tyler and Huo 2002; Schulhofer et al. 2011). Tyler's procedural justice model of policing states that when institutions act with procedural fairness, this generates the legitimacy that helps to sustain and strengthen the ability of legal authorities to elicit compliance and cooperation from those they protect and regulate (Sunshine \& Tyler 2003).

This legitimacy-based framework has been confirmed by an impressive body of empirical results. Links between legitimacy, compliance and cooperation have been shown to be portable across divergent policing contexts (see Tyler \& Jackson, 2013) and in different national contexts, including the United Kingdom (Jackson et al. 2012a; Tankebe 2013), Africa (Tankebe 2009; Bradford et al. 2014; Jackson et al. 2014), Israel (Jonathan-Zamir and Harpaz 2014), and Asia (Cheng 2015). Yet, the extensive literature on procedural justice is narrowly focused. It largely concerns those elements of police behaviour that are immediately visible to the public, such as whether individuals are treated fairly in the context of direct, interpersonal interactions. But policing is a more complex enterprise. It has many elements beyond the immediately observable aspect of individual officers' behaviour within the context of citizen encounters. Over the twentieth century, policing in many Western countries became increasingly complex (Reiss 1992; Reiner 2010), with officers asked to take on a wider array of responsibility beyond mere crime control, like counterterrorism (Tyler et al. 2010; Huq et al. 2011a), sporting event security (Coaffee et al. 2011) and managing the public's fear of crime (Loader and Walker 2007).

In this paper we argue that, by focusing closely on the physical interaction between officers and community members, the procedural justice literature has maintained a conception of policing that has been outpaced by its growing institutional complexity. First, only a handful of studies (for example, Epp et al. 2014; Jackson et al. 2011; see also Tankebe 2013) have recognized the possibility that the distribution of policing resources between different groups might inform normative judgements about police. Second, although legitimacy has been related to the lawfulness of policing (Schulhofer et al. 2011), it remains unclear whether individuals are sufficiently well informed about the specific regulatory constraints on police (Meares et al. in press).

Building on recent work on legal socialization (Tyler and Trinkner 2016; Trinkner et al. 2016), we address the more intuitively plausible hypothesis that legitimacy turns partly on the belief that police generally respect the bounds of their authority, i.e. "bounded authority." As Trinkner and colleagues argue, individuals do not cede unlimited power to legal authorities. They demarcate their lives into domains, some of which are off limits to the intrusion of formal authority. The notion of bounded authority goes beyond the relational nature of procedural justice because it captures processes that represent the misuse of power. Third, and relatedly, police increasingly use surveillance technologies, including CCTV, wiretaps and bulk internet intercepts, to pursue both counterterrorism and also crime control missions (Manning 2011; Harding 2014). These measures have promoted controversy, raising the question whether perceptions of police intrusions on privacy impinge on legitimacy. 
We present a new test of whether a wider array of predicate policing elements predicts different kinds of legitimacy judgements. Our study adds two things to the literature. On the one hand, our survey includes not only standard measures focused on contact with police, procedural justice, and effectiveness in crime-control, but distributive justice, bounded authority, and (relatedly) individual privacy against electronic surveillance. No earlier study has tested a similarly broad array of policing elements.

On the other hand, we build a richer account of the normatively salient aspects of policing to contribute to ongoing debates about the nature of legitimacy (Reisig et al. 2007; Bottoms and 2012; Tyler and Jackson 2013, 2014; Gau, 2014; Johnson et al., 2014). Originally, Tyler (2006) treated legitimacy as a combination of institutional trust and duty to obey. Here, institutional trust signals individuals' assessment of officers' benevolent intentions reflecting their belief that legal authority had the right to power, while duty to obey reflects the sense that the legal authority has the right to dictate appropriate behaviour (Jackson and Gau 2015). This binary conception was then combined and linked to its potential sources in police behaviour. Typically, individual officers' procedural fairness emerged as its single biggest predictor.

Recently, however, an alternative formulation of legitimacy has emerged that a priori defines as constituent elements of legitimacy what Tyler and others view as potential sources of legitimation (Bottoms and Tankebe, 2012; Tankebe 2013; Tankebe et al. 2015). From this formulation, for an individual to believe that the police are legitimate, it simply is the case that he or she must believe that the police are procedurally fair, distributively fair, effective and lawful. If one holds these beliefs, it is not so much that one is likely to also see the police as legitimate. That these beliefs are assumed to constitute the view that the police are legitimate has an important implication. In work by Tyler and colleagues it was an empirical question whether these features may legitimate (with, for example, procedural fairness emerging as more important than effectiveness). But in work by Tankebe and colleagues they are legitimacy, in the sense that they constitute the perceived right to power.

In this paper we consider the value of a different approach of defining and measuring legitimacy. We argue that conceptualizing police legitimacy partly as a 'contentless' sense of normative alignment (Jackson et al. 2012a, 2012b; Tyler \& Jackson 2014; Bradford et al. 2015) yields an important degree of flexibility in the overarching framework. Instead of assuming that legitimacy is "power that embodies" the four elements listed above (Tankebe et al. 2015: 2), we treat legitimacy as an overarching belief that legal authorities act according to societal expectations of rightful conduct in their use of authority. Crucially, this approach allows an empirical investigation of the specific values that 'populate' these norms. By defining legitimacy as normative alignment, we can then estimate which types of police behaviour legitimate the institution in the eyes of citizens.

Drawing on data from a national probability sample of adults in England and Wales, we use our wider array of predicate policing practices to show the value of this approach.

\section{Institutional and behavioural predicates of legitimacy judgements}

Prior work on the sources of police legitimacy tends to focus on a narrow spectrum of behaviour as potential predicates of normative judgement about rightful authority. Tyler (2006) explicitly focused on "the judgements people make about their personal experience." In this initial study, Tyler identified qualities such as neutrality, a willingness to listen, efforts 
to be fair, politeness, and respect for citizens' rights as central elements of procedural justice. Subsequent studies focused on citizens' encounters with police during street stops (Tyler and Fagan 2008; Bradford et al. 2009; Tyler et al. 2014; Tyler et al. 2015), zeroing in upon individuals' perception of whether they were stopped for legitimate reasons, treated fairly, and given an opportunity to tell their side of the story. These elements of procedural justice are found to be associated with legitimacy judgements. These studies have also found only a weak relationship between the effectiveness of the police (e.g., to reduce crime) and legitimacy (e.g. Tyler et al. 2010).

This focus on direct, interpersonal accounts with police officers set the agenda for procedural justice scholarship in several ways. The relationship between both positive and negative contact with police, for example, has also been intensively studied. Early empirical studies finding a striking asymmetry between the large effect of negative contact and the weak effect of positive contact (Skogan 2006) have been challenged in subsequent work (Tyler and Fagan 2008; Bradford et al. 2009; Jackson et al., 2012b). Studies of vehicular stops have focused on interpersonal experiences of fairness in the context of discrete encounters (Epp et al. 2014). Studies of structural dimensions of policing strategy-such as counterterrorism policinghave also tended to focus either on interpersonal encounters or on individuals' perceptions of how police behave when they do encounter suspects (Tyler et al. 2010). Indeed, when studies go beyond respondents' direct experience with police to investigate issues of racial fairness and profiling, the instruments used focus on how individual members of another racial or ethnic group are treated (Huq et al. 2011b). These studies also isolate interpersonal interactions as the most important structural aspect of policing beyond respondents' own experience.

A starting premise of the current study is that members of the public develop perceptions of police behaviour from sources other than immediate interactions with the police. Individuals who have little contact with the police nonetheless have normative judgements of the police based on their beliefs about them, linked to media and educators (Peffley and Hurwitz 2010) and the societal norms and expectations of police conduct that are acquired through legal socialization (Fagan and Tyler 2005; Trinkner and Cohn 2014; Tyler \& Trinkner 2016). Legitimacy may also be a product of authority relations as much as a cause of authority relations (Harkin 2015). If judgements of police legitimacy are founded on information secured not only by direct and indirect interpersonal encounters, but also through a wider range of media and educational sources, it is at least possible that aspects of police organization or behaviour outside the narrow frame of individual encounters will influence legitimacy judgements.

For instance, people may partly judge the legitimacy of the police not only on the procedural fairness they demonstrate in contact with members of the public, but also more broadly on whether officers seem to respect the limits of their power and authority. Authority boundaries represent an essential element of how people define and understand their relationship with legal authorities (Tyler and Trinkner 2016; Trinkner et al. 2016). When the police overstep the boundaries of their authority by encroaching on domains that are off limits - for instance by getting involved in situations they are seen to have no right to be in - individuals may see it as an important breach of the appropriate use of power. Critically, this may go above and beyond traditionally conceived concerns about fair treatment and decision-making, in part because the notion of "bounded authority" references situations and powers that citizens believe that police should or should not have the right to operate within (in terms of situation) and exercise (in terms of power). This is also distinct from whether officers have a legal right 
to intervene, as citizens' tend to have little understanding of law in this regard, yet make judgements about the appropriateness of police action nonetheless (Meares et al. in press).

Moreover, the role of police goes far beyond the provision of physical security from crime through street patrols and traffic enforcement. Police are called upon to play many different roles, ranging from maintaining order at large public events to preventing terrorism attacks, and managing the public's fear of ordinary crime. In response, police have developed complex institutional forms that affect individual citizens' lives both directly and indirectly. For example, as part of their responsibility for protecting against terrorism, police may engage in secret electronic surveillance of telephone calls, email, and social media usage. Police also rely on potentially intrusive technologies to identify ordinary crime and secure evidence by engaging in ongoing monitoring of individuals and even attempting to predict the commission of crimes (Manning 2011). Given that police are tasked with a diverse range of responsibilities that continually expand (e.g., protecting people "from terror"), it is increasingly likely to see public backlash when these tasks purposely or inadvertently lead law enforcement into domains that the public (or parts of it) view as off limits to governmental authority.

In part because of the important role they play in contemporary society, Loader and Mulcahy $(2003,45)$ have argued that police have become a "condensation symbol" for the state more generally. It is through their understanding of the police that people make sense of, and give order to, the world. By emphasizing the role of police as a center of law and order and meaning within a community, Loader and Mulcahy suggest that police practices can influence how people understand their shared aims and endeavors, and develop "collectively validated norms of security and order" (Bradford et al. 2014). The symbolic function of police provides another reason to examine whether a more diverse array of elements-above and beyond direct, interpersonal contact with police during street stops or vehicular stopsinfluence public judgements of legitimacy. It is this that we address in the current study.

\section{Challenges to the conceptualization of legitimacy}

We also contribute to a longstanding debate about how best to conceptualise legitimacy. In an early and influential analysis, Beetham (1991:15) argued that "[t]he key to understanding the concept of legitimacy lies in the recognition that it is multi-dimensional in character." Beetham himself identified three elements: (1) conformity to established rules, (2) which can be justified by reference to beliefs shared by dominant and subordinate groups; with (3) evidence of consent by the subordinate group. In contrast, Tyler (2006: 25) defined legitimacy more parsimoniously as an "acceptance by people of the need to bring their behaviour into line with the dictates of an external authority." In a slightly different formulation, Tyler and Huo (2002:14) identified legitimacy with "the belief that legal authorities are entitled to be obeyed and that the individual ought to defer to their judgements." This definition treats feelings of obligation as central to legitimacy. Consistent with these definitions, the canonical means of operationalizing legitimacy in survey instruments has been to include questions on perceived obligation to obey the law, as well as confidence and trust in legal authorities (Huq et al. 2011a; Tyler 2006: 45; Tyler and Huo 2002; Tyler et al. 2010).

Importantly, none of these studies treat measures of police fairness and effectiveness as part of the scale of legitimacy. Rather, the behaviour, the inferred intentions, and the organizational forms of police are treated as potential predicates of legitimacy. The decision 
by Tyler and others to treat these measures as separate from the concept of legitimacy, however, has recently come under sustained attack. Most notably, Tankebe (2013: 105) argued that "expressions of obligation to obey the directives of legal authorities cannot necessarily be equated to legitimacy". Tankebe claims that a sense of obligation might be explained by a person's belief that police are so powerful they have no choice but to comply with their instructions, as well as by a belief that police authority is normatively justified. The concern that a sense of obligation reflects also dull compulsion, as Tankebe argues, or adaptive preferences motivated by psychological needs and motivations, as Harkin (2015) posits, might imply that legitimacy should not be conceptualised in terms of obligation, but rather in terms of how police conduct is evaluated.

Complementing Tankebe's critique of obligation as a constituent element of legitimacy, Bottoms and Tankebe (2012) have argued for a multidimensional model of legitimacy whereby people's feelings of obligation to obey is treated as an outcome variable explained in part by legitimacy judgements. They argue that legitimacy has four elements. These four elements reflect aspects of police conduct and organization that are stipulated a priori as aspects of rightful power. First, do police behave in a lawful manner and avoid unlawful activities? Second, is policing characterized by distributive fairness by allocating resources fairly among groups with competing claims? Third, police efficacy is an element of legitimacy for the reasons explained in Tankebe (2013), and summarized above. Finally, procedural justice, defined to include both quality of decision-making and quality of treatment, is treated as a component of legitimacy, rather than as a predicate cause.

This study favors an approach that focuses on citizens' more general belief that the police act according to societal expectations about appropriate and desirable conduct - a sense of normative alignment that is an additional component of legitimacy beyond a felt moral duty to obey (Jackson et al. 2012a and 2012b). This way of operationalizing the perceived appropriateness of an institution addresses people's judgements about whether police exercise their authority in accordance with widespread values regarding how their power should be used. But critically, it does not supply the content of these values (like the approach of Tankebe and colleagues). Thus, people will agree with statements like "The police usually act in ways that are consistent with my own ideas of right and wrong" because they believe that the police embody their values about how power should be exercised. Importantly, however, it is an empirical question which values underpin the types of police behaviour that predict normative alignment. If we find that procedural fairness and distributive fairness are key explanatory factors, for instance, then we might conclude that those are the two salient values driving normative expectations about appropriate use of authority.

Finally, when the police act according to citizens' values about how authority should be wielded, this activates a corresponding sense that they, as citizens, should abide by norms regarding appropriate law-related behaviour. This normative alignment model suggests that an ongoing commitment to collective action can be secured by crafting a social identity characterized by a dynamic system of norms that can shape individual members' ongoing commitments (Thomas et al. 2009). And while the concept of normative alignment was initially developed in studies of adult populations in England and Wales, it has also been fielded throughout Europe (Jackson et al. 2011; Hough et al. 2013) and in the United States (Tyler and Jackson 2014). The latter of which included obligation, trust and confidence, and normative alignment as separate elements of legitimacy (see also Bradford et al, 2014, 2015). Each of these three traits, they find, have an independent statistical effect on cooperation (see also Mazerolle et al. 2012). 
We also use measures of duty to obey that were designed to more closely tap into a sense of consensual obligation. Asking people whether it is their 'moral duty' to obey the police aims to elicit a positive sense of obligation - something that one is expected or required to do out of moral or legal obligation, rather than a negative sense of obedience out of fear of sanction or a sense of powerlessness. Duty to obey echoes the Weberian insight that power is transformed into authority when it is seen to be legitimate. When one recognises the authority of the police, one will defer to their orders, not because of fear of punishment or anticipation of reward, but rather because of a sense of moral obligation that is connected to normative justifiability (Tyler 2006; Tyler \& Jackson, 2013). This normatively grounded obligation to obey is assumed to motivate behaviour out of a sense of duty that transcends any sense of shared specific values. One allows the power-holder to dictate appropriate behaviour because one feels a civic responsibility to do so.

\section{Overview}

Figure 1 presents an overview of the basic model of police legitimacy being tested here.

\section{INSERT FIGURE 1 ABOUT HERE}

\section{Data and Methods}

\section{Participants and procedure}

Our data come from a seven-country survey conducted as part of the Fiducia project. Funded by the European Commission as part of the $7^{\text {th }}$ Framework Programme, the project sought to inform policy responses that could speak to both "new" forms of deviant behaviour and "conventional" forms of criminality. We selected data from a national probability sample of adults in England and Wales conducted by Opinion Research Services (the other countries included in the survey were Bulgaria, Finland, Germany, Italy, Lithuania and Turkey). The sample was generated using random digit dialing, with a response rate of $6.3 \%$ (which is typical of telephone surveys), with data weighted to adjust for non-response and deviations from a representative national sample. Post-stratification adjustment involved weighting respondents' responses based upon their demographic characteristics of gender, age, ethnicity, education, income, region and primary language. Once weighted, the sample can be reasonably viewed to approximate a national sample for England and Wales.

\section{Constructs and Measures}

All survey-items used Likert-type response scales, with multiple indicators of each psychological construct of interest.

Dimensions of Police Behaviour. Respondents were asked a series of questions tapping into five dimensions of police behaviour. We consider these to be judgements of the trustworthiness of the police. Trust can be defined as the subjective judgement that a trustor makes about the likelihood of the trustee following through with an expected and valued action under conditions of uncertainty (Jackson \& Gau, 2015). An individual may never be certain whether officers would turn up promptly if called, or whether those officers would treat him or her with respect and dignity once they arrived. But that same individual may nevertheless form judgements about the intentions and capabilities of the officers to fulfil the 
valued functions defined by their social role, and these judgements may powerfully shape that individual's willingness to accept vulnerability by behaving in ways that would otherwise seem risky, like coming to the police with information about a crime.

In the present study we treat these trustworthiness judgements as potential sources of legitimation, with the first judgement being about procedural fairness (Tyler and Blader 2003; Tyler 2006). Respondents were asked to think about the ways by which local police officers interact with citizens at an interpersonal level and make decisions when they interact with community members. As detailed below, in a separate set of questions, respondents asked whether they had had recent contact with police, and if so whether the resulting encounter had involved procedurally just or unjust conduct by the officer.

Second, respondents were asked about the effectiveness of the police, focusing on prevention, interdicting criminals and responding quickly in an emergency. Police efficacy has been treated as an independent variable in many earlier studies of police legitimacy (e.g., Tyler 2006; Tyler et al. 2010). Respondents were asked:

- How successful do you think the police are at preventing crimes in the UK where violence is used or threatened?

- How successful do you think the police are at catching people who commit house burglaries in the UK?

- If a violent crime were to occur near where you live and the police were called, how slowly or quickly do you think they would arrive at the scene?

Third, in a more novel set of questions (see Trinkner et al. 2016), respondents were asked about the frequency by which police officers act in restrained and bounded ways. Bounded authority represents an intermingling of procedural and outcome-related evaluation based on the appropriate use of power. To believe that officers misuse their power - by not respecting people's rights, by arresting people for 'no good reason,' by behaving in illegal ways, etc. - is to believe (a) that they do not follow the correct procedures that derive neutral and fair decision-making and (b) that they engage in concrete actions that overstep their rightful role in society. Respondents were also asked how often (if ever) do they thought the police:

- ... exceed their authority?

- ...abuse their power?

- ....act as if they are above the law?

- ...violate people's freedoms?

- ...get involved in situations that they have no right to be in?

- ...harass and intimidate people?

Fourth, respondents were asked about issues of police surveillance and privacy. The five questions reflected a range of ways in which people use technology to collect communications often viewed as private:

- How often would you say the police...listen to the content of telephone calls of people who are not criminals?

- How often would you say the police...track where people who are not criminals are using the GPS signal on their phones? 
- How often would you say the police...monitor what people who are not criminals say on the internet?

- The police respect people's privacy when they conduct investigations and enforce the law (agree/disagree)

- The police respect people's privacy except when the person being investigated is a member of certain racial or ethnic group (agree/disagree)

Finally, like Tankebe (2013) and Jackson et al. (2011) we investigate whether the distribution of policing resources between different social groups is a normatively relevant consideration. Respondents were asked:

- Thinking about when victims report crimes in the UK, do you think the police treat rich people worse, poor people worse, or are rich and poor treated equally? Rich people treated worse; poor people treated worse; rich and poor treated equally

- And when victims report crimes in the UK, do you think the police treat some people worse because of their race or ethnic group, or is everyone treated equally? People from minority racial or ethnic backgrounds treated worse; people from the same race or ethnic group as most the UK people treated worse; everyone treated equally regardless of their race or ethnic group

Unlike the other four dimensions of policing behaviour - which we treat as latent variables, see the analytical strategy and scaling sections below - we combine answers to the two distributive fairness questions in a more pragmatic way. For each respondent we count the number of times that they say that 'poor people' and 'people from minority racial or ethnic backgrounds' are treated worse.

Contact with police. In order to analyze the distinct effect of direct, interpersonal contact with the police on legitimacy judgements, respondents were asked whether police officers had made contact with them for any reason in the past two years. Out of the 1,004 respondents who answered this question, 272 (27\%) reported having experienced at least one police-initiated encounter, and were subsequently asked two questions about their experience: first, whether the police made fair decisions; and second, whether the police treated them fairly. The same questions were asked regarding whether they had contacted or approached the police for any reasons. Public-initiated contact was frequent, with $665(66 \%)$ individuals reporting the experience. We therefore constructed two separate indices of procedurally fair or unfair contact with law enforcement: officer-initiated and citizen-initiated.

Police legitimacy. First, respondents' felt obligation to obey police authority was assessed by tapping into their expressed intention to acquiesce to police directives and decisions, even when they may not agree with the police. Respondents were asked:

Now some questions about your duty towards the police in the UK, where duty means you have a moral responsibility to obey the police. To what extent do you feel it is your moral duty to...

- ... back the decisions made by the police because the police are legitimate authorities?

- ...back the decisions made by the police even when you disagree with them?

- ...do what the police tell you even if you don't understand or agree with the reasons? 
Second, respondents completed items assessing the degree to which they felt that the police acted in ways that aligned with their own set of salient values regarding appropriate and desirable conduct (where those salient values were not specified in the measures). Respondents were asked to agree or disagree with these statements:

- The police usually act in ways that are consistent with my own ideas of right and wrong.

- The police can be trusted to make the right decisions

- The police generally have the same sense of right and wrong as I do.

\section{Results}

\section{Analytical strategy}

We first examine the scale properties of our five aspects of police trustworthiness. We take a reflective approach to measurement that implies a series of connected assumptions - that these are unobservable psychological constructs, that changes in observed variables or indicators are taken to reflect changes in a latent construct, and that our imperfect behavioural indicators are subject to measurement error. We also assume that the correlations between the measures are by virtue of them measuring the same underlying concept of interest, and further that the variance in each indicator that is not shared is measurement error.

We then assess the degree to which perceptions of police treatment and decision-making, bounded authority, police effectiveness, distributive justice, and surveillance concerns are linked to recent police contact using structural equation modeling (SEM). We present our results graphically. We should stress that our analytical strategy seeks to clarify what can be said about the correlations in the broader population between contact with the police, beliefs about diverse aspects of observed and unobserved police behaviour, and different forms of police legitimacy. The direction of the arrows in the path analysis is not meant to imply that we have demonstrated causality. By collecting data from a representative (weighted) sample, we estimate conditional correlations in the UK adult population.

\section{Scaling}

Table 1 summarizes the results from a series of Confirmatory Factor Analysis (CFA) models using MPlus 7.2 (with indicators set as categorical). The approximate fit statistics suggest that, while a series of three-factor models fit the data poorly, the four-factor model fits well (note that the distributive fairness index is a single manifest indicator - see the constructs and measures section above). We thus find empirical support that trust in police effectiveness, trust in police procedural justice, trust in police distributive justice, bounded authority and surveillance/privacy can be treated as separate judgements. While they are strongly correlated, they nevertheless seem to be empirically distinct.

\section{INSERT TABLE 1 HERE}

Table 2 presents correlations, means and variances of latent variables estimated within the four-factor confirmatory factor-analysis model. We see moderately strong bivariate associations between two pairs: (a) police effectiveness and procedural fairness $(r=.60)$, and (b) procedural fairness and bounded authority $(\mathrm{r}=.66)$. In the four-factor model, most factors 
loadings and $\mathrm{R}^{2} \mathrm{~s}$ are relatively high, indicating good scale reliability. For trust in police effectiveness the standardized factor loadings range from .67 to .80 , and the $\mathrm{R}^{2} \mathrm{~s}$ range from .45 to .63 . For trust in police procedural fairness the standardized factor loadings range from .82 to .86 , and the $\mathrm{R}^{2} \mathrm{~s}$ range from .67 to .75 . For trust in police bounded authority the standardized factor loadings range from .74 to .93 , and the $\mathrm{R}^{2} \mathrm{~s}$ range from .50 to .86 . For surveillance practices the standardized factor loadings range from .51 to .97 , and the $\mathrm{R}^{2} \mathrm{~s}$ range from .27 to .95 .

\section{INSERT TABLE 2 ABOUT HERE}

\section{Linking direct contact with trust in the police}

It is important to understand how direct, interpersonal contact with police predicts judgements relates to other potential predicates of police trustworthiness (Tyler \& Fagan 2008). Contact is directly related to procedural justice concerns, but it is not clear whether it will be associated with other predicates such as bounded authority and distributive justice.

Figure 2 reports our first set of findings, using SEM to link contact with the police to judgements about five elements of police conduct and organization. In this model, two dichotomous variables are used for police-initiated contact: (a) contact experienced as something other than fair, and (b) contact experienced as fair; and two dichotomous variables are used for public-initiated contact: (c) contact experienced as something other than fair and (d) contact experienced as fair. Correlations between these four variables to the five judgements of trustworthiness are then estimated.

The fit of the model is acceptable according to approximate fit statistics. Consistent with prior studies, we see that contact experienced as something other than fair is a negative predictor for all components of policing behaviour except for surveillance. The strongest statistical effect is for procedural justice. Contact experienced as fair had a slightly weaker, but this time positive, statistical effect on all measures except surveillance and bounded authority.

In sum, divergent experiences of contact with police are more strongly correlated with judgements about procedural justice, and less strongly linked to judgements about distributive justice and police efficacy. There is a yet weaker correlation to both bounded authority and surveillance judgements. Only a relatively small amount of variance of each trustworthiness judgement, however, is explained by contact (the $\mathrm{R}^{2} \mathrm{~s}$ range from $1 \%$ to $9 \%$ ). This implies that judgements about various dimensions of policing conduct and organization cannot be reduced to assessments based on interpersonal contact alone.

\section{What legitimizes the police in the eyes of the policed?}

We next examine the extent to which legitimacy is predicted by the various attitudinal judgements. As described earlier, rather than stipulating as a theoretical matter the contents of legitimacy, we seek to explore how different elements of police conduct might be normatively salient in relation to different kinds of legitimacy judgements.

Figure 3 reports key findings from a fitted SEM that links the five aspects of police conduct and organization under analysis here to our bifurcated concept of legitimacy. We find that $61 \%$ of the variance of normative alignment is explained by an additive combination of the 
five trustworthiness judgements related to police conduct and organization. Procedural justice and bounded authority are the strongest positive predictors. This indicates that when people believe that the police in their community are fair in their personal interactions with citizens and respect the limits of their power and authority, they are also more likely to believe that the same officers acts according to one's values about how authority should be wielded.

\section{INSERT FIGURE 3 ABOUT HERE}

In addition, we find that $28 \%$ of the variance of duty to obey is explained by the five aspects of police conduct we measure. Among those, three (effectiveness, procedural justice and bounded authority) are moderately strong positive predictors. This indicates that when people believe that the police in their community are effective, fair and respect the limits of their power and authority, they are also more likely to feel a contentless duty to obey police commands and directives. Third, we find that the measure of police surveillance has no statistical effect on legitimacy judgements of either kind. Finally, normative alignment and duty to obey are positively correlated, even after adjusting for effectiveness, fairness, bounded authority and surveillance ( $\mathrm{r}=.40)$.

Figure 4 reports the results of a model that also includes a path from normative alignment to duty to obey. The theory motivating this model is that people feel a moral duty to obey the police in large part because they believe that the police are an appropriate, just and proper institution (cf. Jackson et al., 2012a, 2012b). Furthermore, when the police behave in accordance with societal values about the appropriate role/duties of the law, people's own values about their responsibilities/obligations as citizens are activated in response (here, to feel a moral duty to obey the police).

\section{INSERT FIGURE 4 ABOUT HERE}

This seems to be borne out by the evidence. Normative alignment does act as a statistical mediator. First, three of the five components of policing behaviour measured (effectiveness, procedural justice, and bounded authority) have a strong correlation with normative alignment. Distributive justice and surveillance measures, however, do not seem to be related to normative alignment. Next, normative alignment appears to mediate powerfully the key associations with duty to obey. Finally, the magnitudes of the effect sizes of procedural justice and bounded authority on duty to obey are each reduced considerably. Surveillance and distributive justice measures, in contrast, respectively fail to reach significance or are only weakly significant. Table 3 summarises an effect decomposition run using MPlus 7.2.

\section{INSERT TABLE 3 ABOUT HERE}

The relation of police effectiveness to both normative alignment and on duty to obey as illustrated in Figure 4 is worth stressing. Although police effectiveness is affiliated to normative alignment, it provides an even stronger prediction of the duty to obey controlling for the effect of normative alignment. This suggests that the effect of police effectiveness is distinct and different from the other components of policing related to normative alignment, such as procedural justice and bounded authority. Figure 5 illustrates the distinct pathways from procedural justice and bounded authority to the duty to obey on the one hand, and between effectiveness and the duty to obey on the other.

\section{INSERT FIGURE 5 ABOUT HERE}


Finally, we bring in contact with the police to a new fitted SEM. Table 4 summarizes in numerical form the coefficients associated with the pathways from interpersonal encounters with the police to the two measures of legitimacy, normative alignment and the duty to obey. Each row of the table presents the marginal effect of a specific form of contact (positive or negative) with police upon one strand of legitimacy judgement (either normative alignment or the duty to obey) as mediated by either procedural justice or bounded authority.

\section{INSERT TABLE 4 ABOUT HERE}

\section{Discussion}

Our paper began with the observation that procedural justice scholarship has adopted a narrow focus on the components that may legitimate the police in the eyes of citizens. Prior studies have tended to focus on interpersonal contact, and on the concepts of procedural fairness and effectiveness, and only intermittently upon issues like bounded authority and distributive justice. Moreover, no previous study has attended to the effect of surveillance practices. Our first goal was to fill that gap by analyzing the effect of direct, unmediated contact with police and also five general aspects of police conduct and behaviour on legitimacy. A second goal was to show the usefulness of a 'contentless' definition of legitimacy that is defined and analyzed separately from predicate forms of police behaviour. By exploring whether a broader range of police behaviours can legitimize or delegitimize the police to different degrees, we defined people's perceptions of these behaviours not as legitimacy, but rather as possible sources of legitimation with contingent empirical effects.

To begin, we found that direct, interpersonal contact with police explains only a small amount of the variance of judgements about general forms of police conduct and organization, and that some of these judgements are also predicates of legitimacy. This finding is consistent with the recent literature on legal socialization (Fagan \& Tyler 2005; Trinkner \& Cohn 2014; Trinkner \& Tyler 2016), which suggests individuals accrue legitimacy-relevant information about police from a plurality of sources as they mature from childhood to adulthood. Individuals in our sample seemed to attend to a wide range of observed and unobserved elements of policing when forming legitimacy judgements.

Most importantly, procedural justice and bounded authority were the two key predictors of normative alignment, and their effect on the felt duty to obey was largely mediated via normative alignment. Hence, when people thought that the police treated citizens fairly, made decisions in objective ways, and also respected the limits of their power, they also tended to think that the police act in ways that were consistent with their sense of right and wrong. This sense of normative alignment in turn seemed to induce a felt moral duty to obey the police. In contrast, we found that judgements of police effectiveness had a direct statistical effect on the felt duty to obey that was not mediated by normative alignment. Finally, whereas distributive justice judgements had a weak relation to the duty to obey and no apparent effect on normative alignment, measures of surveillance were uncorrelated with either kind of legitimacy judgement.

Because we find powerful affiliations between procedural justice, and in particular direct and unmediated experiences with police, and legitimacy judgements, our results are consistent with the large body of procedural justice research on that point. In other respects, however, 
our results extend the foundational procedural justice model in a number of ways. We emphasize five points here.

First, the isolation of a statistical effect from bounded authority on legitimacy is a threshold insight finding. Previous procedural justice studies have explored the quality of police behaviour as measured against objective standards of fairness, impartiality and respect. This study suggests an additional metric should receive further attention - that police do not abuse the authority that has been vested in them, but rather comply with shared norms of the appropriate official conduct. This is distinct, we note from the concept of legality, which others have posited as important albeit without evidence. The effect we find is from socially derived conceptions of appropriate behaviour, rather than legally defined parameters of police authority, which the public is largely unaware of (Meares et al., 2014). As a result, it may be that a policing measure is authorized by law (such as the authority to conduct stops and searches in urban areas), but nonetheless violates individuals' sense of bounded authority. It may also be that a species of police behaviour falls outside of legal boundaries, but is not perceived as a violation of the social bounds of police authority.

A second important finding relates to effectiveness. In contrast to procedural justice and bounded authority, police effectiveness judgements had strong links to felt duty to obey but this relationship did not appear to be mediated by normative alignment. Rather, a perception that the police are effective does not appear to shape normative alignment with the police. Even if police are not perceived as acting in desirable, correct and expected ways, they still seem able to some extent to instil a felt duty to obey merely by dint of perceived effectiveness. Hence, by decomposing legitimacy into two elements, it is possible to see how different aspects of policing conduct and behaviour have an effect on one strand of legitimacy beliefs but not the other.

Three, a striking - and unexpected-null result in this study is the absence of an effect of electronic surveillance upon judgements of police legitimacy. For a number of reasons, we anticipated some relationship between the perception that police use intrusive investigative techniques that impinge on private forms of communication, such as email and social media, and legitimacy judgements. In the aftermath of disclosures by Edward Snowden about the extent of secret data collection by both British and also American governments, there was a vigorous public debate about the value and appropriateness of such surveillance programs. Moreover, an earlier study of British Muslims' experience with counterterrorism policing (Huq et al. 2011b) found that one predictor of procedural justice judgements was the extent to which respondents believed that their community was subject to electronic surveillance. There are two possible ways of interpreting our finding in light of that earlier result. First, the earlier result might reflect a judgement not about surveillance per se, but rather about the distributive equity of a policing strategy that placed all the weight of maintaining public security on religious and ethnic minorities. Second, the absence of an effect might be explained by a belief that even if the government pervasively uses electronic surveillance, the respondent (or the respondent's community) is not the object of such investigative methods.

The fourth important result is as follows: by teasing out the range of predicates for legitimacy judgements, and showing that different predicate aspects of police conduct and organization influence, this study points to the analytic gains from treating the predicates of policing behaviour as distinct from legitimacy judgements, and also from a plural understanding of legitimacy. Unlike Tankebe and colleagues, who a priori defined legitimacy in terms of procedural fairness, distributive fairness, effectiveness and lawfulness, our approach treats 
the latter as predicates, and as potential legitimating factors, allowing a number of useful analytic distinctions to be drawn. It draws attention to the different contributions that various aspects of policing can make to legitimacy judgements. Distribution justice, we suggest, simply does not seem to have the impact that procedural justice and bounded authority do. It also allows investigation of the different pathways such influence can take. Here, the mediating role played by normative alignment for procedural justice and bounded authority, but not for police effectiveness, suggest a more complex understanding of legitimacy than the fourfold concept offered by Bottoms and Tankebe. Finally, the distinction between the predicates of legitimacy and police legitimacy itself (in terms of police behaviour) invites consideration of new predicates of legitimacy. Although the factor tested here-police surveillance-had no statistical effect on legitimacy, this kind of investigation of the diverse forms and missions of policing, and their influence on legitimacy, is cut short by the a priori definition of legitimacy offered by Tankebe and colleagues.

Fifth, and relatedly, this study also suggests the value of defining legitimacy along two specific dimensions. One key expectation is that citizens should feel a moral duty to obey the police. We operationalized the perceived right to power as normative alignment, i.e. a 'content-free' sense of shared values. Survey questions like 'the police usually act in ways that are consistent with my sense of right and wrong' do not specify the relevant sense of right and wrong (Jackson et al., 2012a). Rather, it is an empirical question which aspects of police behaviour - and what societal values about how power should be exercised 'populate' that sense of appropriateness. Then, believing that officers act appropriately may activate a reciprocal sense among citizens that they, too, should act in normatively appropriate ways that support the role of the legal system and legal authorities in society.

This approach to defining legitimacy may have a particular advantage when it comes to cross-cultural and cross-national work. It allows for the empirical investigation of whether different populations (for example, in different countries, or different groups in the same society) focus on different aspects of police organization and behaviour in making legitimacy judgements (cf. Jackson et al. 2011). If one specifies the values that 'populate' the meaning of legitimacy - like, for instance, procedural fairness, distributive fairness, effectiveness and lawfulness - then one assumes that to be legitimated, legal authorities need to act in ways that fulfill those values. Yet, people in different countries legitimate authorities on different bases. The current approach allows one could assess whether procedural fairness, distributive fairness, effectiveness and lawfulness are each more important predictors of the perceived right to power (cf. Hough et al. 2013).

The most important limitation of the current study is that the available data is not sufficient to show causation. The survey instrument employed in this study, although capable of generating nationally representative data, allows us to estimate conditional correlations in the population, but does not allow us to observe the dynamic effect of different sorts of experience and knowledge of policing. Moreover, we do not claim to have investigated all potential predicates of police legitimacy, or to have determined the weight assigned to each predicate by different populations. Future studies should analyze how the institutional predicates of police legitimacy differ between ethnic communities and also between national contexts. It may also be that the predicates of police legitimacy are sensitive to developments in policing strategies and missions. If police take on new roles, it is not clear that the predicates of legitimacy will remain unchanged. We suggest that future studies investigate not just the causal question, but the possibility of variation in the behavioural predicates of legitimacy within different populations under different social circumstances. 
To close, we have demonstrated that legitimacy has a wider array of predicates in police conduct and organization than generally recognized. By treating the latter as predicates of rather than as components of legitimacy, we hope to have shown the value of treating legitimacy as a contentless source of normative alignment, and of remaining open to the contingent effects of different elements of policing on normative judgements about police legitimacy. 


\section{References}

Beetham, D. (1991). The legitimation of power. London: Macmillan.

Bottoms, A., and Tankebe, J. (2012). Beyond procedural justice: A dialogic approach to legitimacy in criminal justice, Journal of Criminal Law and Criminology, 102, 1, 119_ 170.

Bradford, B., Hohl, K., Jackson, J. and MacQueen, S. (2015). Obeying the rules of the road: Procedural justice, social identity and normative compliance, Journal of Contemporary Criminal Justice, 31, 151-170.

Bradford, B., Jackson, J. and Stanko, E. (2009). Contact and confidence: Revisiting the impact of public encounters with the police, Policing and Society, 19, 1, 20-46.

Bradford, B., Murphy, K., and Jackson, J. (2014). Officers as mirrors: Policing, procedural justice and the (re)production of social identity, British Journal of Criminology, 54, 4, 527-550.

Cheng, K. K. Y. (2015). Prosecutorial procedural justice and public legitimacy in Hong Kong, British Journal of Criminology, available online doi: 10.1093/bjc/azv106azv106.

Coaffee, J., Fussey, P., and Moore, C. (2011). Laminated security for London 2012: Enhancing security infrastructures to defend mega sporting events, Urban Studies, 48, 15, 3311-3327.

Epp, C. R., Maynard-Moody, S., and Haider-Markel, D. P. (2014). Pulled over: How police stops define race and citizenship. University of Chicago Press.

Gau, J. M. (2014). Procedural justice and police legitimacy: A test of measurement and structure. American Journal of Criminal Justice, 39, 187-205.

Fagan, J., and Tyler, T. R. (2005). Legal socialization of children and adolescents, Social Justice Research, 18, 3, 217-242.

Harding, L. (2014). The Snowden files: The inside story of the World's most wanted man. New York: Vintage.

Harkin, D. (2015). Police legitimacy, ideology and qualitative methods: A critique of procedural justice theory, Criminology and Criminal Justice, 15, 5, 594-612.

Hough, M., Jackson, J. and Bradford, B. (2013). The governance of criminal justice, legitimacy and trust, in Body-Gendrot, S., Lévy, R., Hough, M. Snacken, S. and Kerezsi, K. (eds.) Routledge handbook of European criminology. Routledge, pp. 243265.

Huq, A. Z., Tyler, T. R., \& Schulhofer, S. J. (2011a). How do the purposes and targets of policing influence the basis of public cooperation with law enforcement? Psychology, Public Policy and Law, 17, 419-450.

Huq, A. Z., Tyler, T. R., \& Schulhofer, S. J. (2011b). Mechanisms for eliciting cooperation in counterterrorism policing: A study of British Muslims. Journal of Empirical Legal Studies, 8, 728-761.

Jackson, J. (2015). On the dual motivational force of legitimate authority, in Bornstein, B. H. and Tomkins, A. J. (eds.) Cooperation and compliance with authority: The role of institutional trust. 62nd Nebraska Symposium on Motivation. New York: Springer, pp. 145-166.

Jackson, J., Asif, M., Bradford, B. and Zakar, M. Z. (2014). Corruption and Police Legitimacy in Lahore, Pakistan, British Journal of Criminology, 54, 6, 1067-1088, doi: 10.1093/bjc/azu069.

Jackson, J., Bradford, B., Hough, M., Kuha, J., Stares, S. R., Widdop, S., Fitzgerald, R., Yordanova, M. and Galev, T. (2011). Developing European indicators of trust in justice, European Journal of Criminology, 8, 4, 267-285. 
Jackson, J., Bradford, B., Hough, M., Myhill, A., Quinton, P., and Tyler, T. R. (2012a). Why do people comply with the law? Legitimacy and the influence of legal institutions, British Journal of Criminology, 52, 6, 1051-1071.

Jackson, J., Bradford, B., Stanko, E. A. and Hohl, K. (2012b), Just authority? Trust in the police in England and Wales. Routledge.

Jackson, J. and Gau, J. (2015). Carving up concepts? Differentiating between trust and legitimacy in public attitudes towards legal authority, in Shockley, E., Neal, T. M. S., PytlikZillig, L. and Bornstein, B. (eds.) Interdisciplinary perspectives on trust: Towards theoretical and methodological integration. New York: Springer, pp. 49-69.

Johnson, D., Maguire, E.R., and Kuhns, J.B. (2014). Public perceptions of the legitimacy of the law and legal authorities: Evidence from the Caribbean, Law and Society Review, 48, 4, 947-978.

Jonathan-Zamir, T., and Harpaz, A. (2014). Police understanding of the foundations of their legitimacy in the eyes of the public: The case of commanding officers in the Israel national police, British Journal of Criminology, 54, 3, 469-489.

Loader, I., and Walker, N. (2007). Civilizing security. Cambridge University Press.

Loader, I., and Mulcahy, A. (2003). Policing and the condition of England: Memory, politics and culture. Oxford: Oxford University Press.

Manning, P. (2011). The technology of policing: Crime mapping, information technology, and the rationality of crime control. New York: New York University Press.

Mazerolle, L., Antrobus, E., Bennet, S., and Tyler, T. R. (2012). Shaping citizen perceptions of police legitimacy: A randomized field trial of procedural justice, Criminology, 51, 1, 33-64.

Meares, T. L., Tyler, T. R., \& Gardener, J. (in press). Lawful or fair? How cops and laypeople view good policing. Journal of Criminal Law and Criminology.

Peffley, M., and Hurwitz, J. (2010). Justice in America: The separate realities of blacks and whites, Cambridge: Cambridge University Press.

Reiner, R. (2007). Law and order: An honest citizen's guide to crime and control. London: Polity.

Reisig, M. D., Bratton, J. and Gertz, M. G. (2007). The construct validity and refinement of process-based policing measures, Criminal Justice and Behaviour, 34, 1005-1027.

Reiss, A.J. (1992). Police organization in the twentieth century, Crime and Justice, 15, 5197.

Schulhofer, S., Tyler, T., and Huq, A. (2011). American policing at a crossroads: Unsustainable policies and the procedural justice alternative, Journal of Criminal Law and Criminology, 101, 2, 335-375.

Skogan, W.G. (2006). Asymmetry in the impact of encounters with the police, Policing and Society, 16, 2, 99-126.

Sunshine, J., and Tyler, T.R. (2003). The role of procedural justice and legitimacy in shaping public support for policing, Law and Society Review, 37, 513-548.

Tankebe, J. (2009). Public cooperation with the police in Ghana: Does procedural fairness matter?, Criminology, 47, 4, 1265-1293

Tankebe, J. (2013). Viewing things differently: The dimensions of public perceptions of legitimacy, Criminology, 51, 1, 103-135.

Tankebe, J., Reisig, M.D., \& Wang, X. (2015). A multidimensional model of police legitimacy: A cross-cultural assessment, Law and Human Behavior, available online.

Thomas, E. F., McGarty, C., and Mavor, K. I. (2009). Aligning identities, emotions, and beliefs to create commitment to sustainable social and political action. Personality and Social Psychology Review, 13, 3, 194-218. 
Trinkner, R., and Cohn, E. S. (2014). Putting the "social" back in legal socialization: Procedural justice, legitimacy, and cynicism in legal and non-legal authorities, Law and Human Behaviour, 38, 6, 602.

Trinkner, R., Jackson, J. and Tyler, T. R. (2016). Bounded authority: Power, constraint and legitimation, Yale Law School working paper.

Tyler, T. R. and Huo, Y. J. (2002). Trust in the law. New York: Russell-Sage.

Tyler, T. R. and Trinkner, R. (2016). Legal socialization in an era of mistrust: Fostering popular legitimacy in the law. Manuscript in preparation.

Tyler, T. R. (2006). Why people obey the law $\left(2^{\text {nd }}\right.$ edition). New Haven: Yale University Press.

Tyler, T. R. and Jackson, J. (2014). Popular legitimacy and the exercise of legal authority: Motivating compliance, cooperation and engagement, Psychology, Public Policy and Law, 20, 1, 78-95.

Tyler, T. R., and Fagan, J. (2008). Why do people cooperate with the police?, Ohio State Journal of Criminal Law, 6, 231-275.

Tyler, T. R., and Jackson, J. (2013). Future challenges in the study of legitimacy and criminal justice. In J. Tankebe, and A. Liebling (Eds.), Legitimacy and criminal justice: An international exploration (pp. 83-104). Oxford: Oxford University Press.

Tyler, T. R., Jackson, J. and Mentovich, A. (2015). On the consequences of being a target of suspicion: Potential pitfalls of proactive police contact, Journal of Empirical Legal Studies, 12, 4, 602-636. 
Table 1. Fit statistics for a series of fitted confirmatory factor analysis models

\begin{tabular}{||l|l|c|c|c|c|c|c|c||}
\hline \multicolumn{1}{|c|}{ Model } & $\begin{array}{c}\text { Chi- } \\
\text { Square }\end{array}$ & df & $\boldsymbol{p}$ & RMSEA & $\begin{array}{c}\text { RMSEA } \\
\text { 90\% CI }\end{array}$ & CFI & TLI \\
\hline M1 & $\begin{array}{l}\text { Three-factors (combining } \\
\text { bounded authority and } \\
\text { surveillance) }\end{array}$ & 1624 & 99 & $<.0005$ & .124 & $.119-.129$ & .911 & .892 \\
\hline $\mathbf{M 2}$ & $\begin{array}{l}\text { Three-factors (combining } \\
\text { bounded authority and } \\
\text { procedural fairness) }\end{array}$ & 1432 & 99 & $<.0005$ & .116 & $.111-.121$ & .922 & .906 \\
\hline $\mathbf{M 3}$ & $\begin{array}{l}\text { Three-factors (combining } \\
\text { procedural fairness and } \\
\text { surveillance) }\end{array}$ & 1876 & 99 & $<.0005$ & .134 & $.128-.139$ & .897 & .875 \\
\hline $\mathbf{M 4}$ & $\begin{array}{l}\text { Three-factors (combining } \\
\text { procedural fairness and } \\
\text { effectiveness) }\end{array}$ & 1030 & 99 & $<.0005$ & .097 & $.091-.102$ & .946 & .934 \\
\hline M5 & Four-factors & 495 & 95 & $<.0005$ & .065 & $.059-.070$ & .977 & .971 \\
\hline \hline
\end{tabular}

Data: Fiducia UK survey 
Table 2. Correlations between elements of trust

\begin{tabular}{|l|c|c|c|c|c||}
\hline & 1 & 2 & 3 & 4 & 5 \\
\hline 1. Procedural fairness & - & & & & \\
\hline 2. Distributive fairness & $.36^{* * * *}$ & - & & & \\
\hline 3. Effectiveness & $.60^{* * *}$ & $.27 * * *$ & - & & \\
\hline 4. Bounded authority & $.66^{* * *}$ & $.43^{* * *}$ & $.40^{* * *}$ & - & \\
\hline 5. Surveillance practices & $.18^{* * *}$ & $.11^{* * *}$ & .00 & $.43^{* * * *}$ & - \\
\hline
\end{tabular}

Data: Fiducia UK survey. These are correlations between latent variables estimated within a confirmatory factor analysis model with categorical indicators. Means of all latent variables were set to zero. Variances for latent variables are $.75, .63, .55$ and .27 (respectively). * $p<0.05, * * p<0.01, * * * p<0.001$. 
Table 3. Indirect statistical effects of the trustworthiness judgements on duty to obey, directly and indirectly via normative alignment

\begin{tabular}{||l|c|c|c|c|}
\hline PATHWAY VIA & COEFF. & SE & COEFF./SE & P-VALUE \\
\hline Distributive fairness to duty to obey & -.082 & .032 & -2.562 & .010 \\
\hline $\begin{array}{l}\text { Distributive fairness to duty to obey via } \\
\text { normative alignment }\end{array}$ & -.008 & .016 & -0.484 & .629 \\
\hline Procedural fairness to duty to obey & -.075 & .061 & -1.234 & .217 \\
\hline $\begin{array}{l}\text { Procedural fairness to duty to obey via } \\
\text { normative alignment }\end{array}$ & .231 & .036 & 6.390 & $<.001$ \\
\hline Effectiveness to duty to obey & .150 & .044 & 3.445 & .001 \\
\hline $\begin{array}{l}\text { Effectiveness to duty to obey via } \\
\text { normative alignment }\end{array}$ & .052 & .019 & 2.720 & .007 \\
\hline Boundaries to duty to obey & .041 & .057 & .719 & .472 \\
\hline $\begin{array}{l}\text { Boundaries to duty to obey via } \\
\text { normative alignment }\end{array}$ & .198 & .030 & 6.641 & $<.001$ \\
\hline Surveillance to duty to obey & -.013 & .041 & -0.305 & .761 \\
\hline $\begin{array}{l}\text { Surveillance to duty to obey via } \\
\text { normative alignment }\end{array}$ & -.029 & .020 & -1.418 & .156 \\
\hline
\end{tabular}

Standardized coefficients estimated within the structural equation model (see Figure 2). COEFF = regression coefficient. $S E=$ standard error . 
Table 4. Indirect statistical effects of the procedural fairness of respondents' direct, interpersonal encounters with the police on perceived police legitimacy (both normative alignment and the duty to obey)

\begin{tabular}{||l|c|c|c|c|}
\hline PATHWAY VIA & COEFF. & SE & COEFF./SE & P-VALUE \\
\hline $\begin{array}{l}\text { Stop (other than fair) to procedural } \\
\text { justice to normative alignment }\end{array}$ & -.037 & .014 & -2.663 & .008 \\
\hline $\begin{array}{l}\text { Stop (other than fair) to bounded } \\
\text { authority to normative alignment }\end{array}$ & -.035 & .013 & -2.657 & .008 \\
\hline $\begin{array}{l}\text { Stop (fair) to bounded authority to } \\
\text { normative alignment }\end{array}$ & .037 & .015 & 2.496 & .013 \\
\hline $\begin{array}{l}\text { Contact (other than fair) to procedural } \\
\text { justice to normative alignment }\end{array}$ & -.076 & .018 & -4.231 & $<.001$ \\
\hline $\begin{array}{l}\text { Contact (other than fair) to bounded } \\
\text { authority to normative alignment }\end{array}$ & -.037 & .014 & -2.714 & .007 \\
\hline $\begin{array}{l}\text { Contact (fair) to procedural justice to } \\
\text { normative alignment }\end{array}$ & .048 & .016 & 2.911 & .004 \\
\hline $\begin{array}{l}\text { Stop (other than fair) to procedural } \\
\text { justice to normative alignment to duty } \\
\text { to obey }\end{array}$ & -.020 & .008 & -2.549 & .011 \\
\hline $\begin{array}{l}\text { Stop (other than fair) to bounded } \\
\text { authority to normative alignment to } \\
\text { duty to obey }\end{array}$ & -.019 & .007 & -2.579 & .010 \\
\hline $\begin{array}{l}\text { Stop (fair) to bounded authority to } \\
\text { normative alignment to duty to obey }\end{array}$ & .020 & .008 & 2.415 & .016 \\
\hline $\begin{array}{l}\text { Contact (other than fair) to procedural } \\
\text { justice to normative alignment to duty } \\
\text { to obey }\end{array}$ & -.041 & .011 & -3.819 & $<.001$ \\
\hline $\begin{array}{l}\text { Contact (other than fair) to bounded } \\
\text { authority to normative alignment to } \\
\text { duty to obey }\end{array}$ & -.020 & .007 & -2.600 & .008 \\
\hline $\begin{array}{l}\text { Contact (fair) to procedural justice to } \\
\text { normative alignment to duty to obey }\end{array}$ & .026 & .009 & 2.800 & .005 \\
\hline
\end{tabular}

Standardized coefficients estimated within the structural equation model (see Figure 2). $C O E F F=$ regression coefficient . $S E=$ standard error . 
Figure1. Study overview

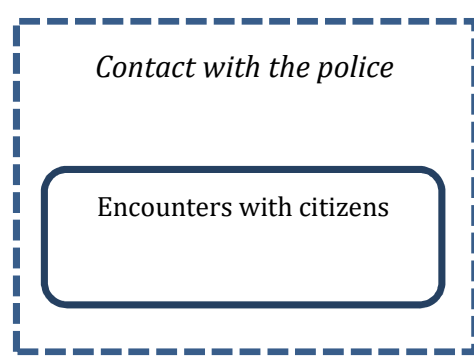

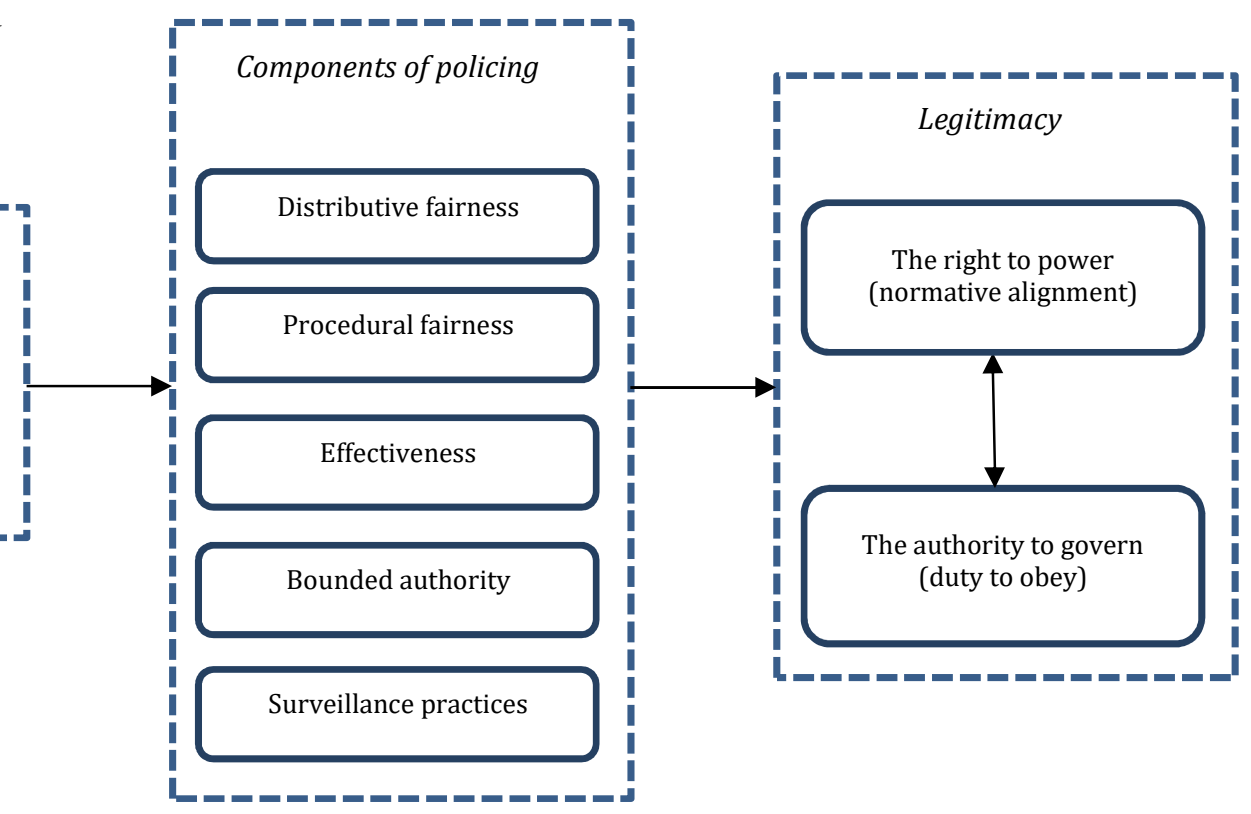




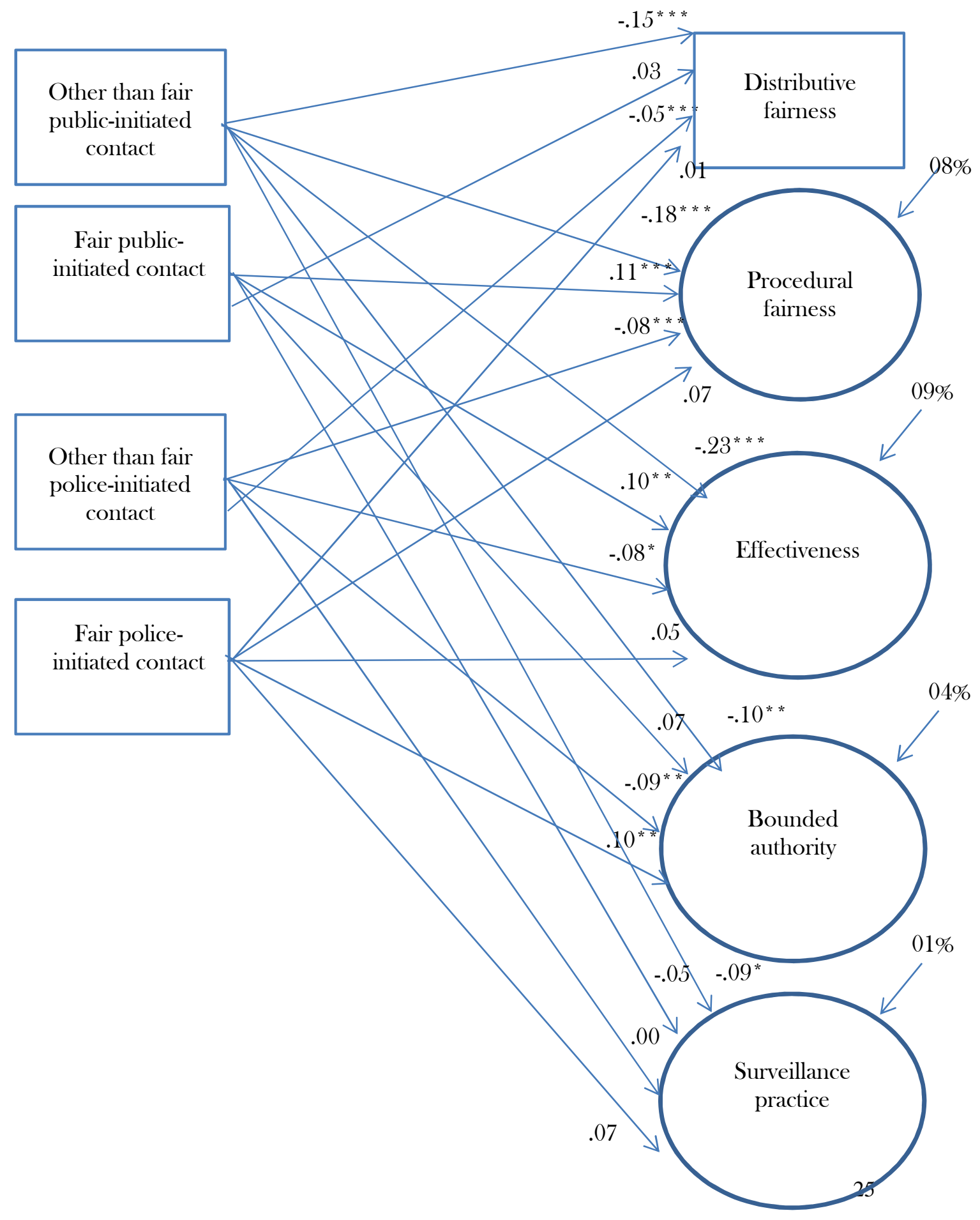

Figure 2. SEM linking contact to trust in the police

SEM with categorical indicators using Mplus 7.2 Exact fit statistics: Chi-Sq 535, 139 df, p<.001 Approximate fit statistics: CFI .978, TLI .970 RMSEA .053 [90\%CI .049-.058]

NOTE: measurement models omitted for visual ease. Standardized regression coefficients provided 


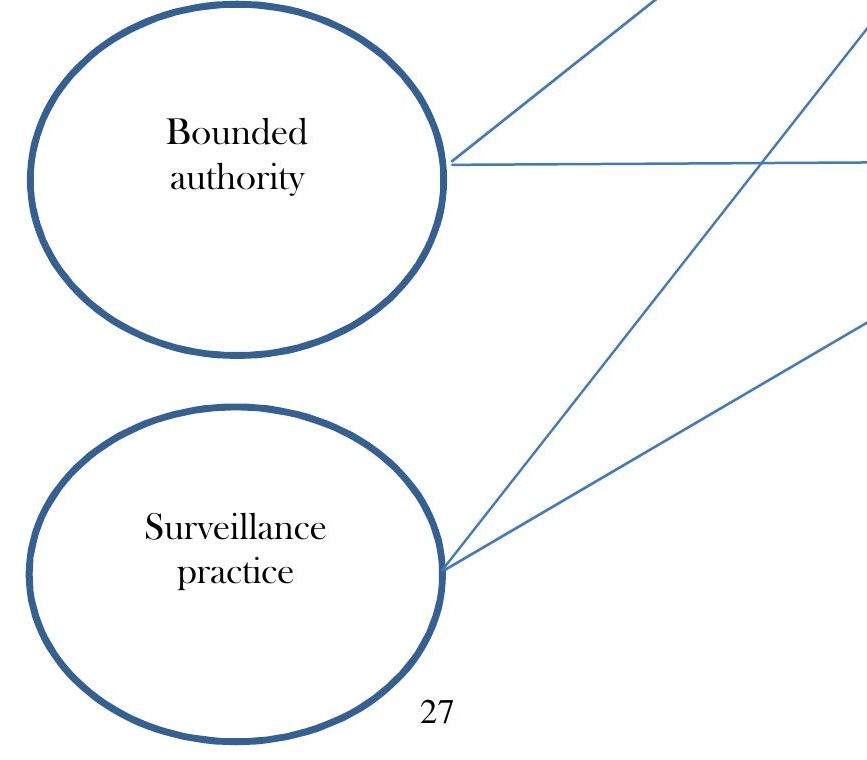


Figure 5. Two Pathways from Policing Predicates to the Duty to Obey

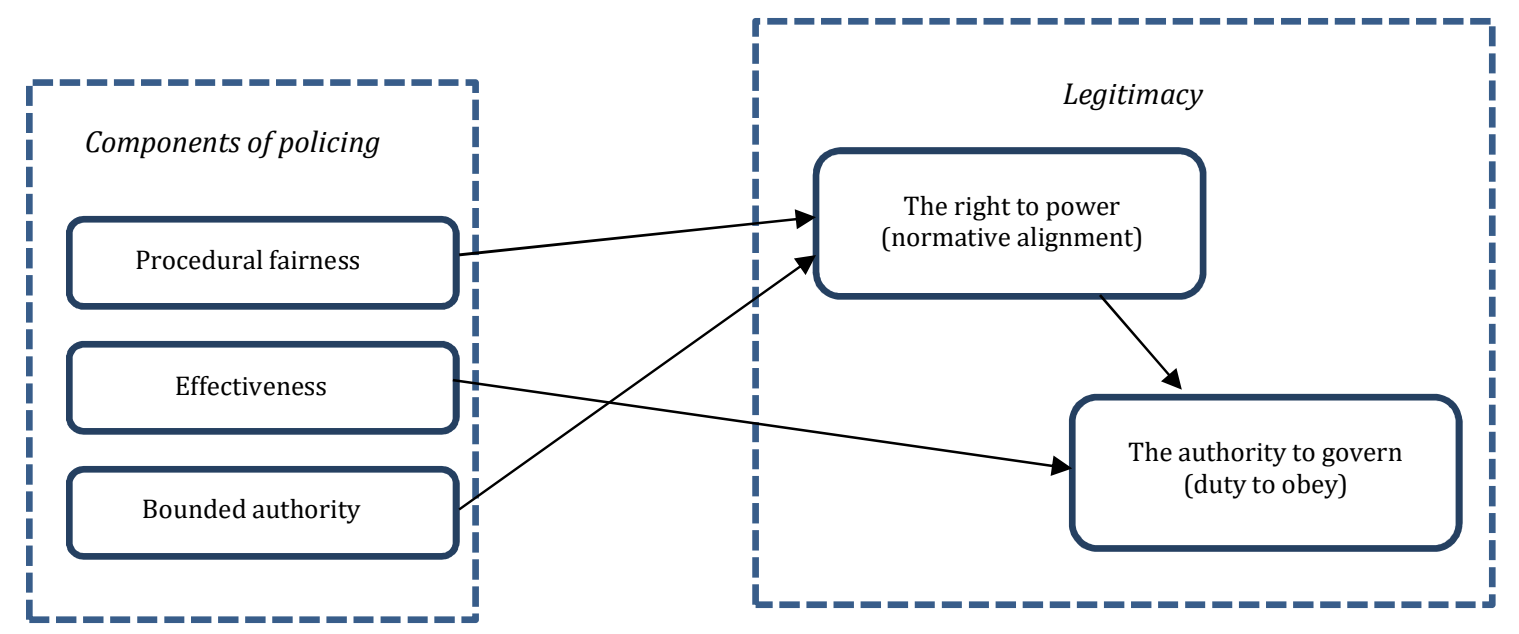

